\title{
Possible Windermere Rifts in the Mesoproterozoic Belt Basin of the Montana Rockies
}

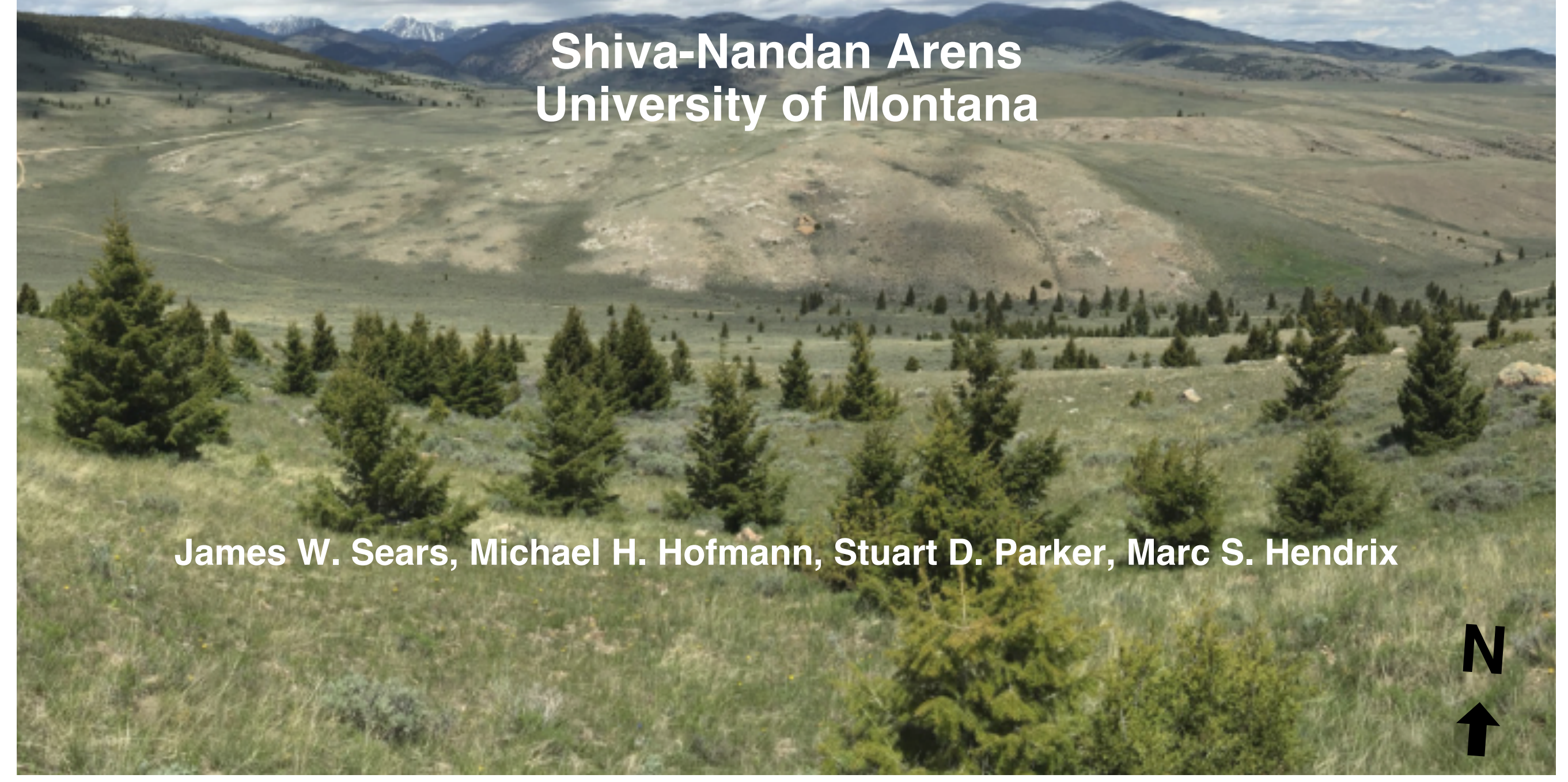




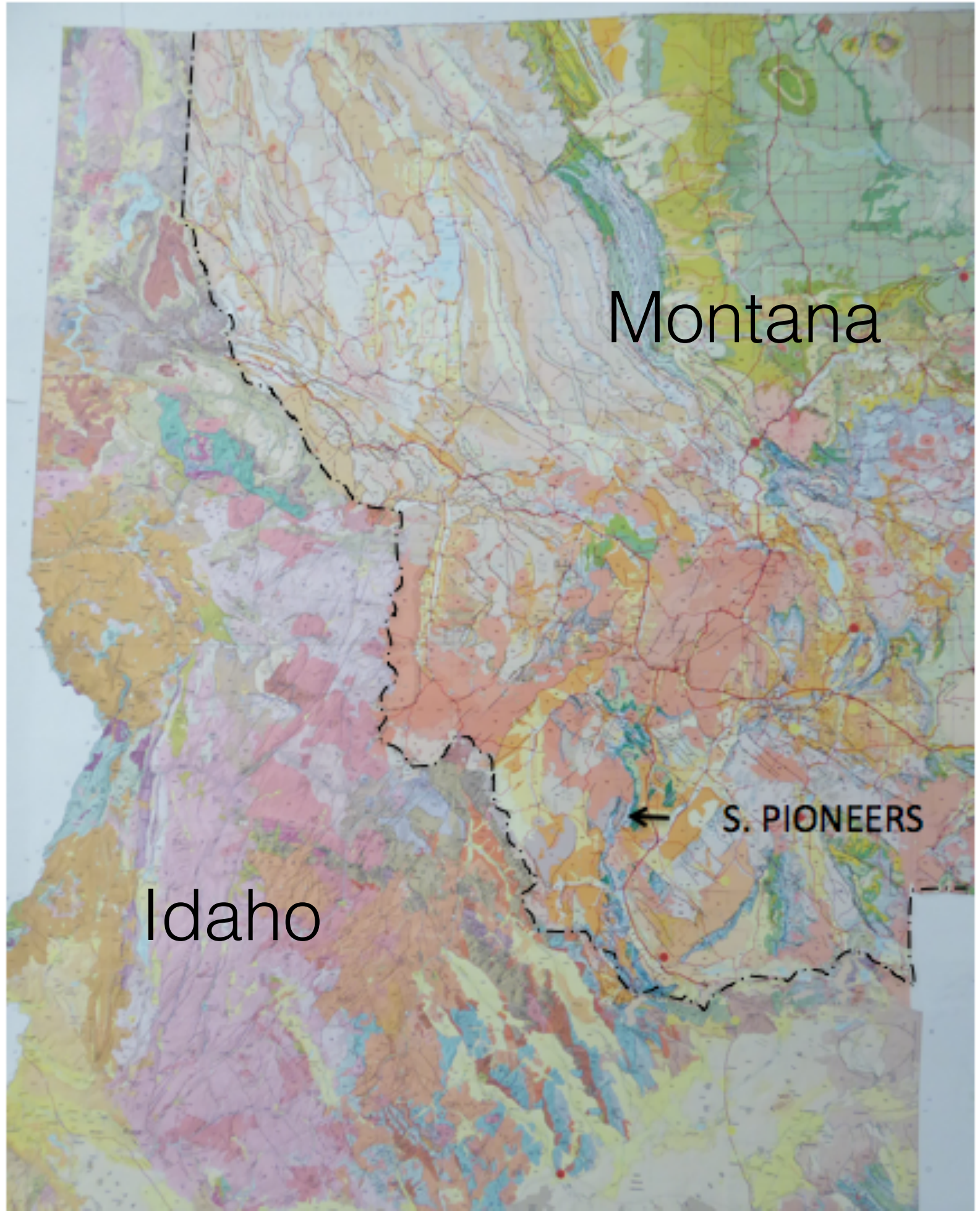

MBMG, IGS 


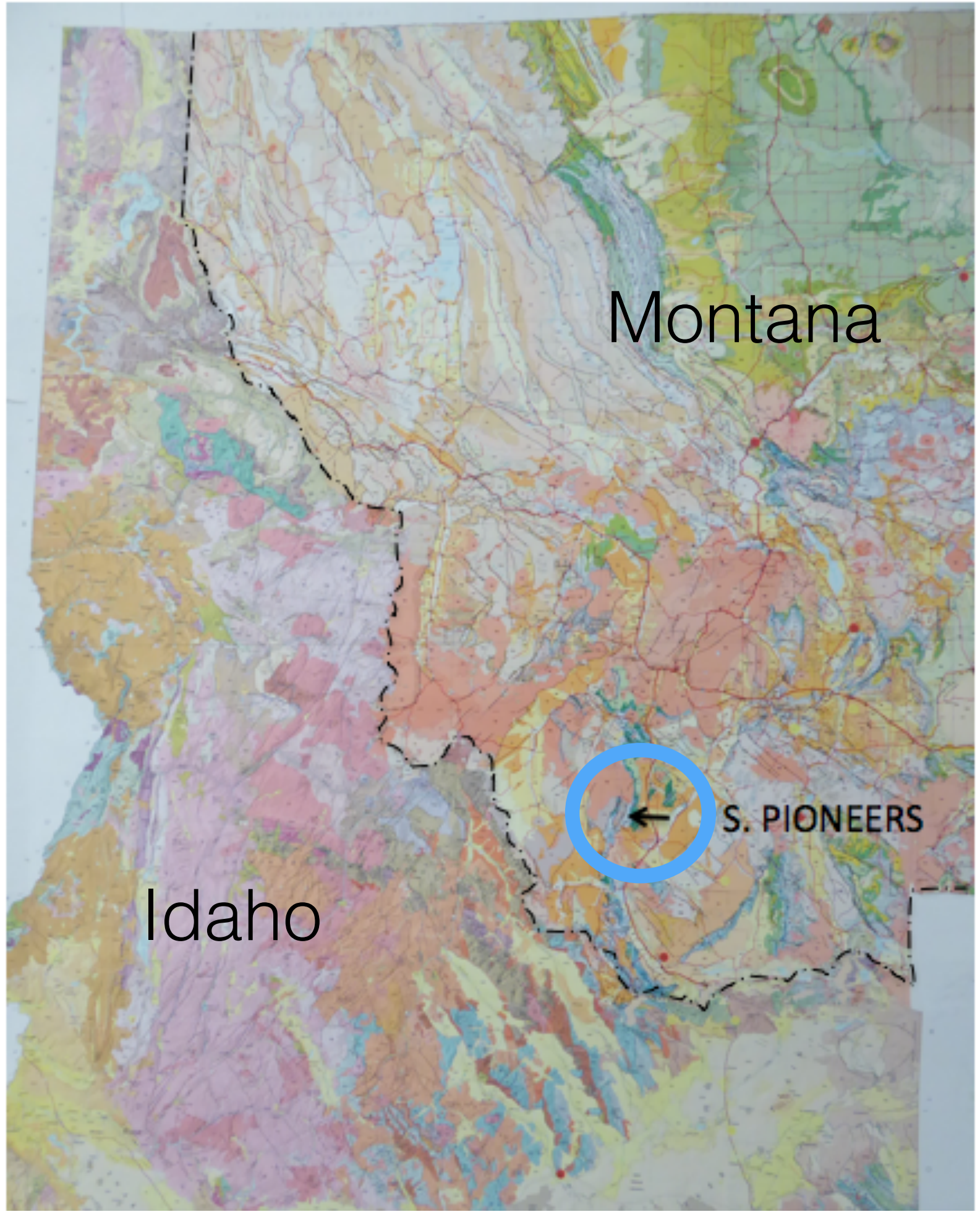

MBMG, IGS 
North America and the Windermere Supergroup:

\begin{tabular}{|l|} 
- extensive \\
- helps characterize \\
rifting at the margin \\
of Laurentia \\
- Structural signature \\
not previously \\
recognized in MT
\end{tabular}

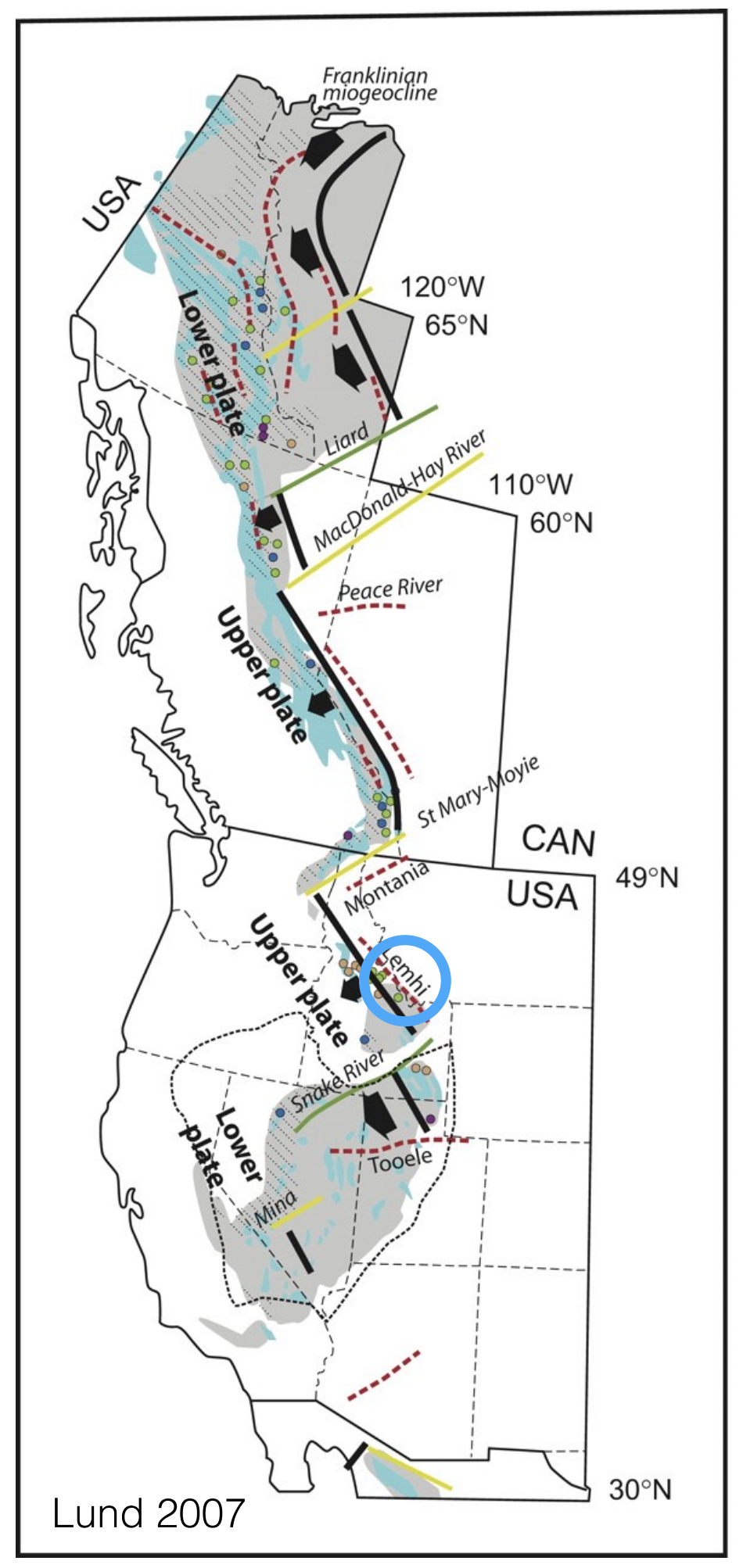




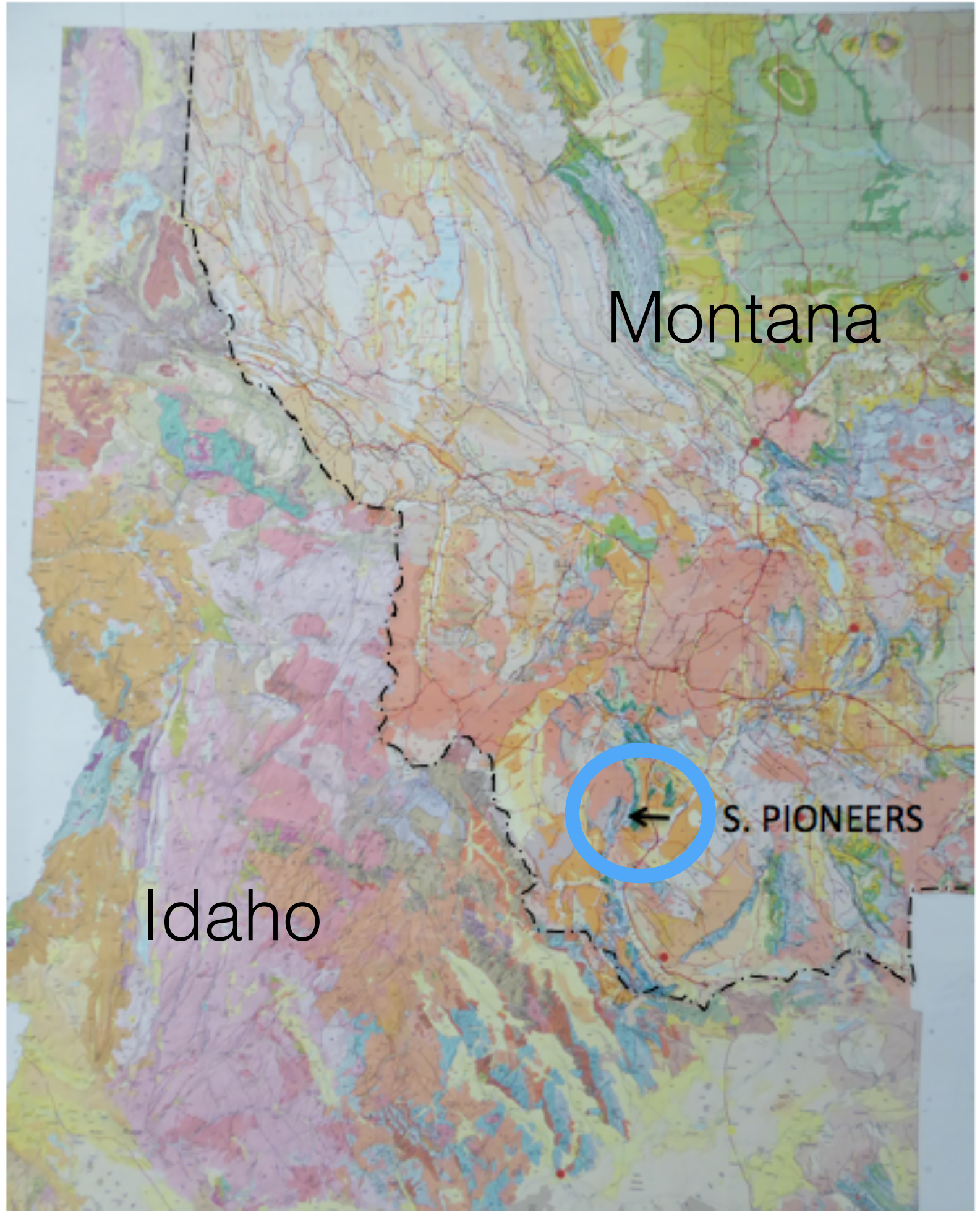

MBMG, IGS 


\section{The Humbolt Anticline}

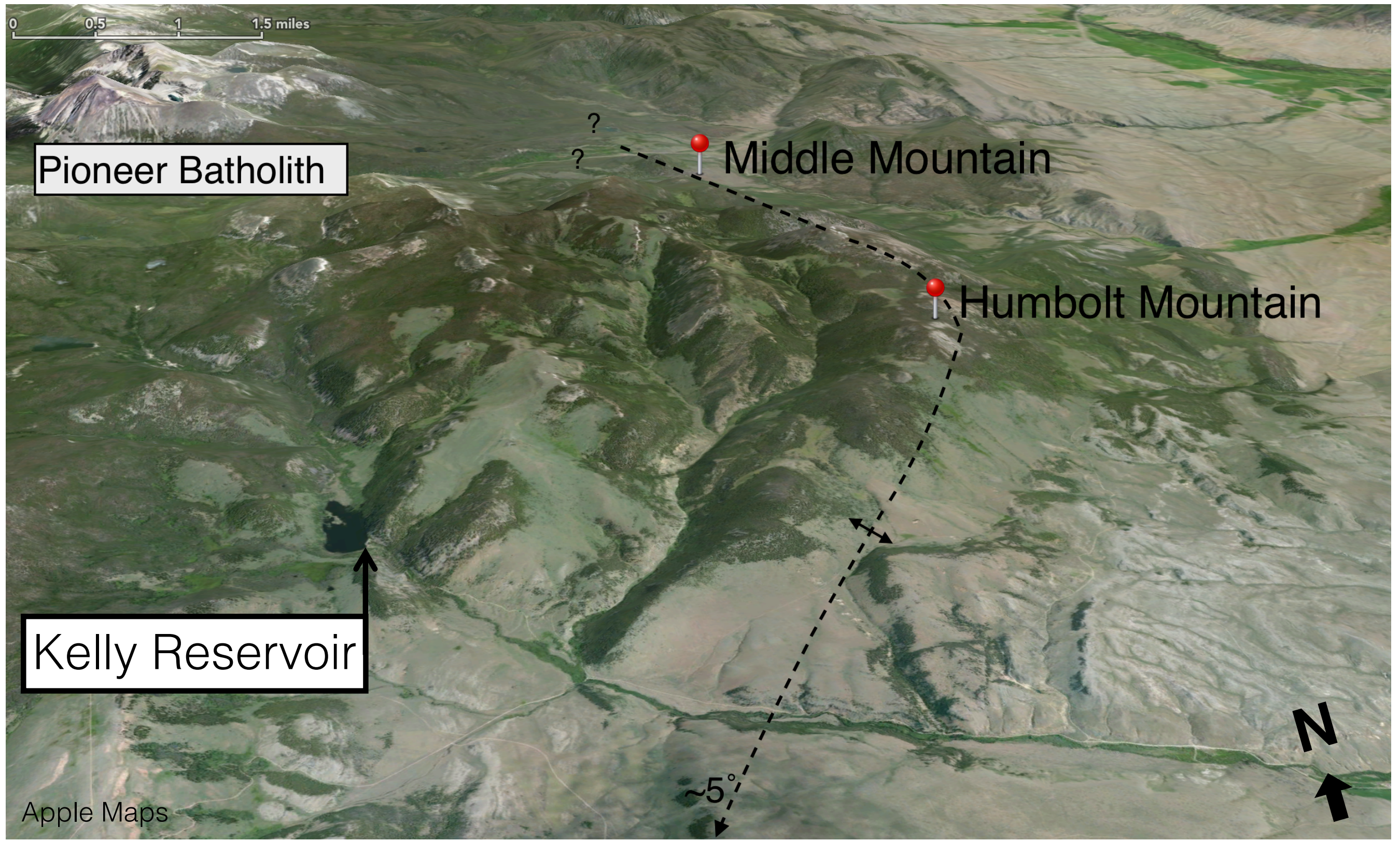






Geologic Field Map, Kelly Reservoir 


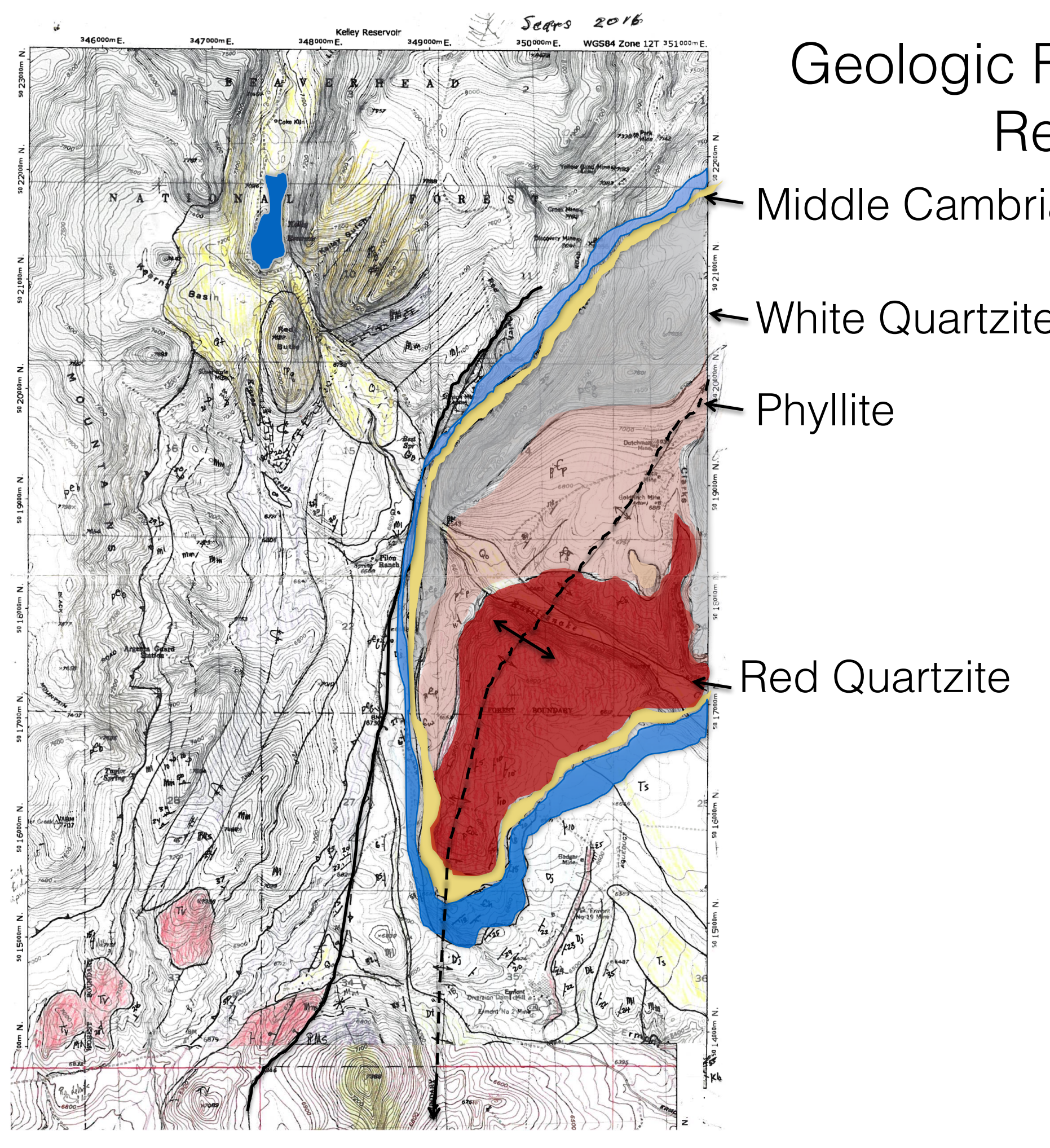




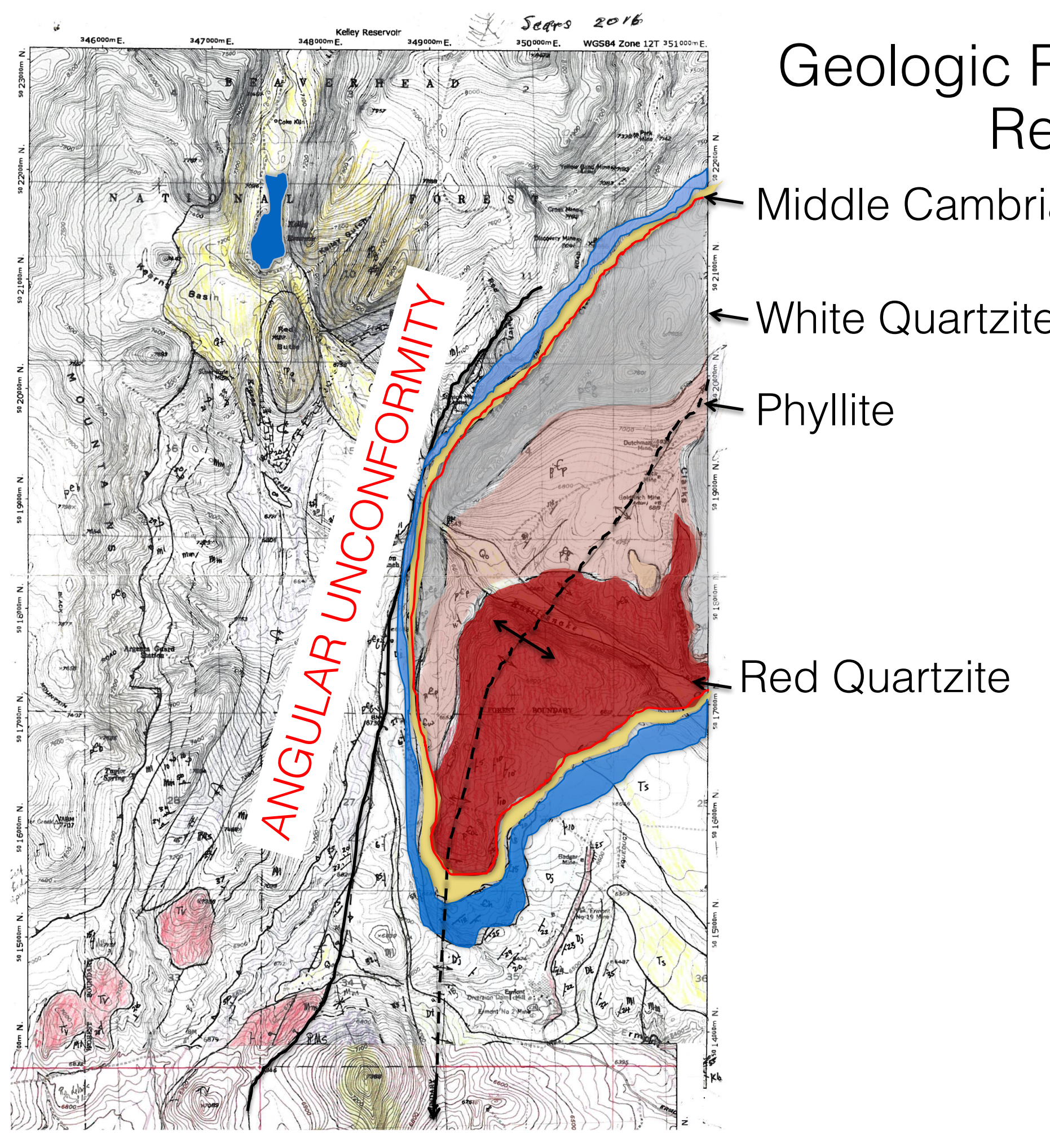




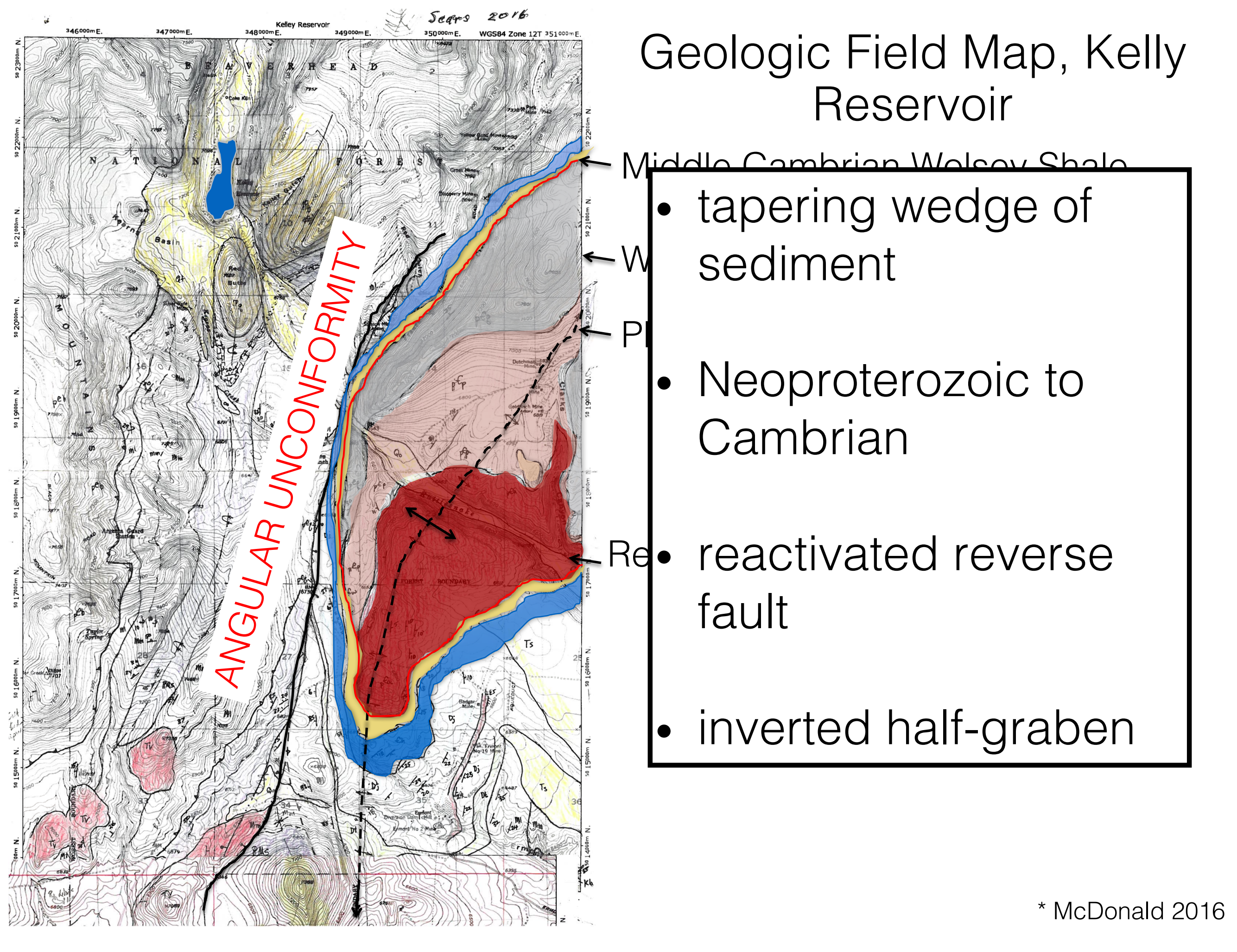




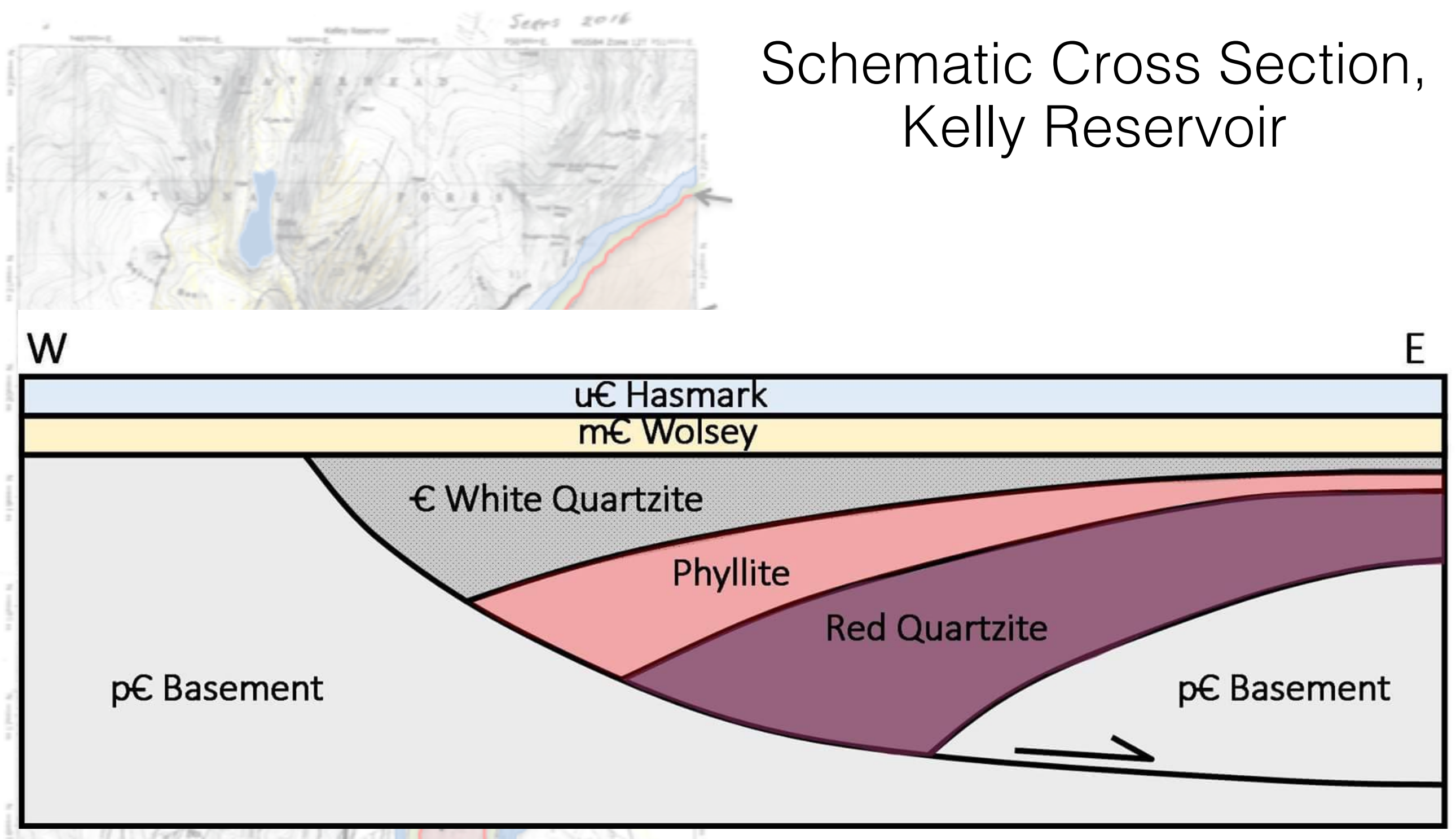




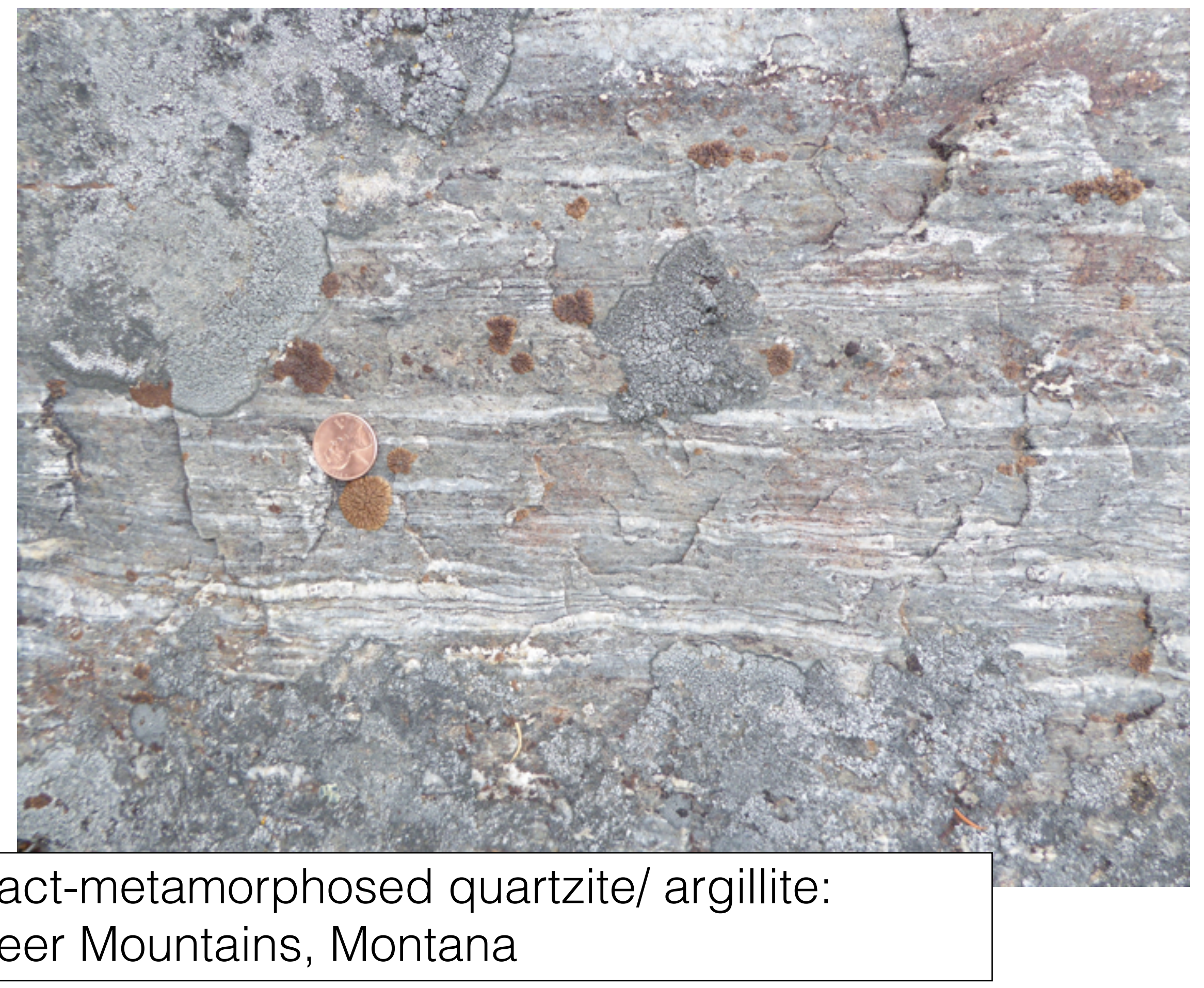




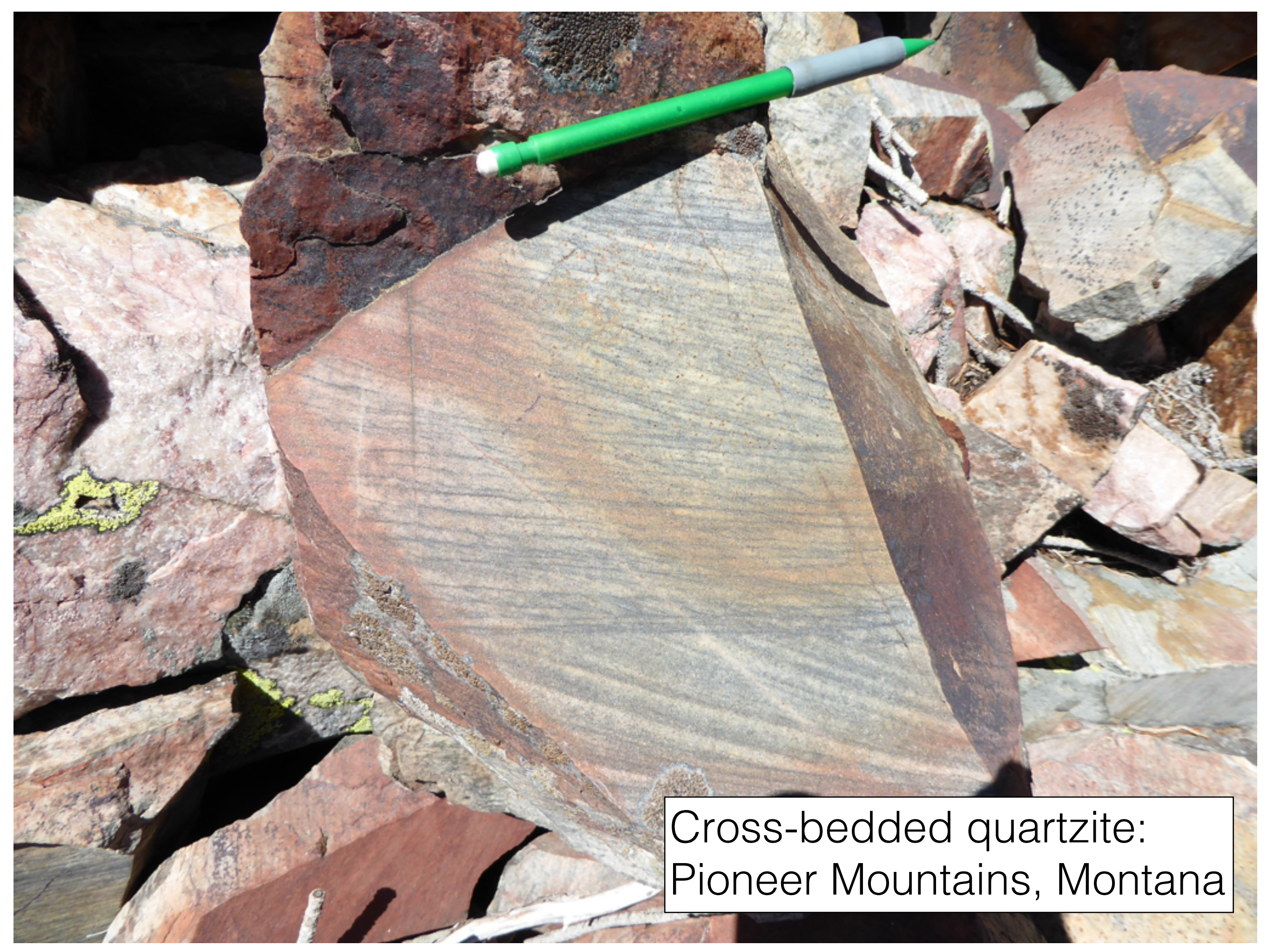




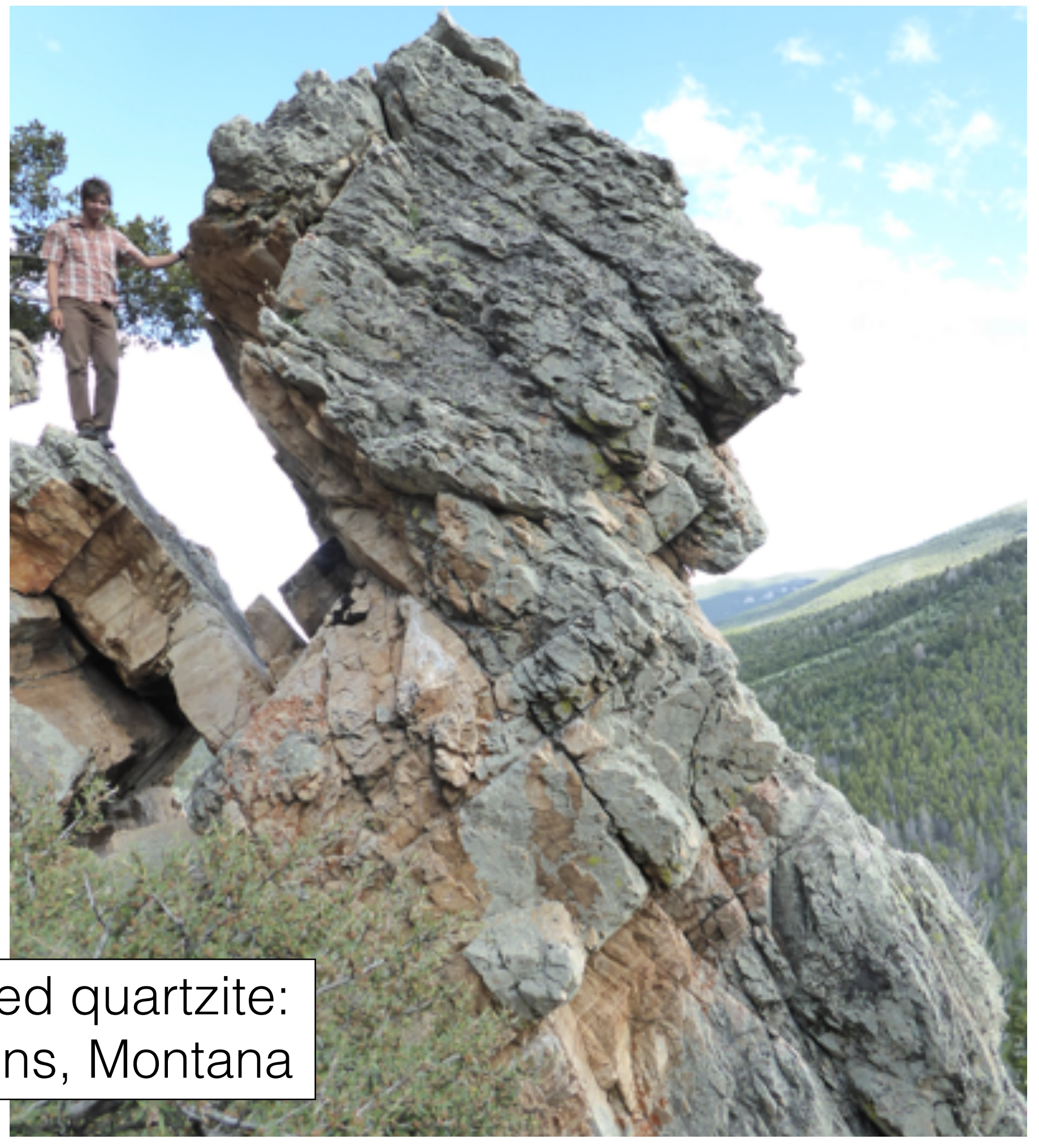

Massively bedded quartzite: Pioneer Mountains, Montana 


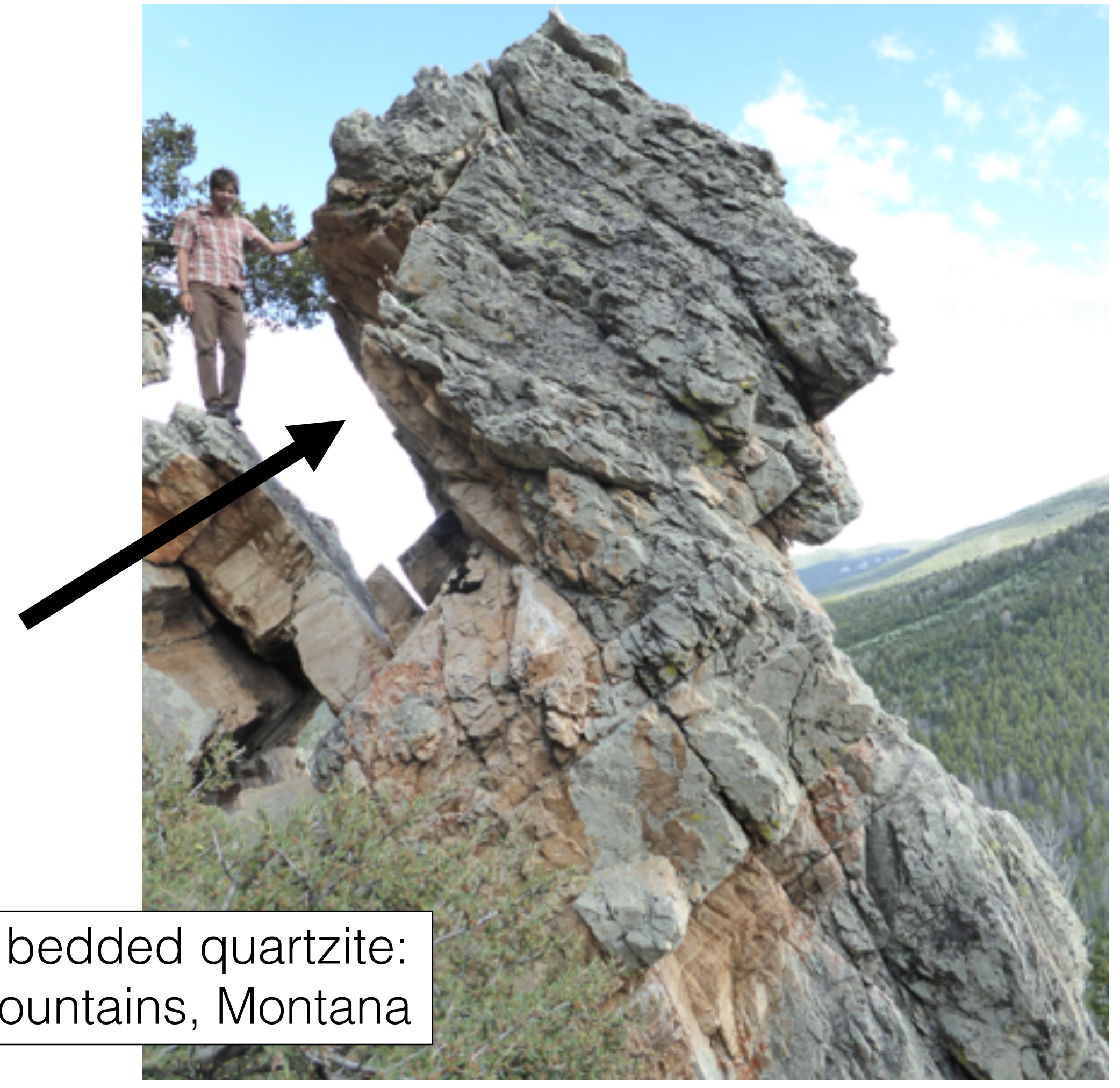




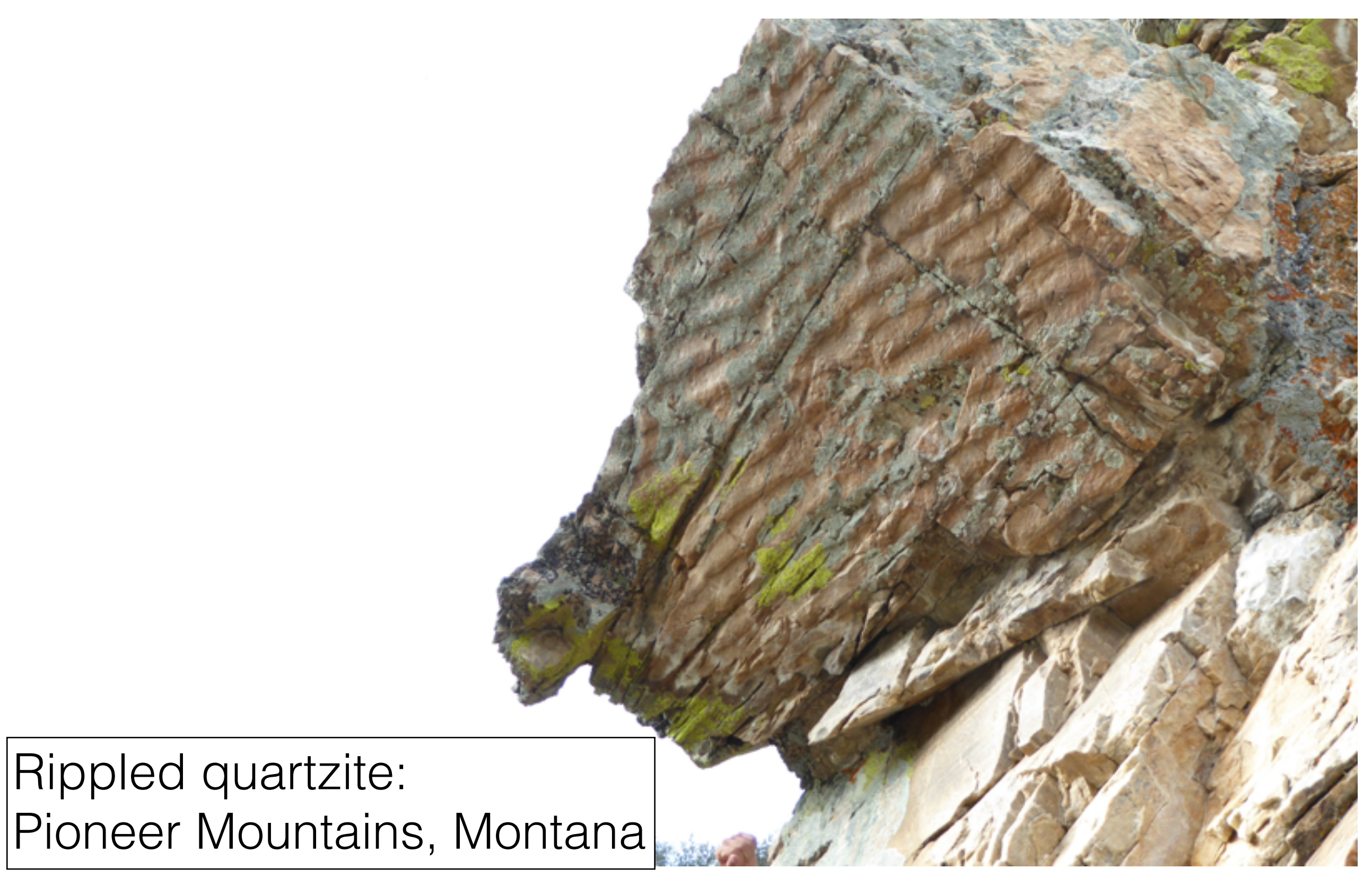




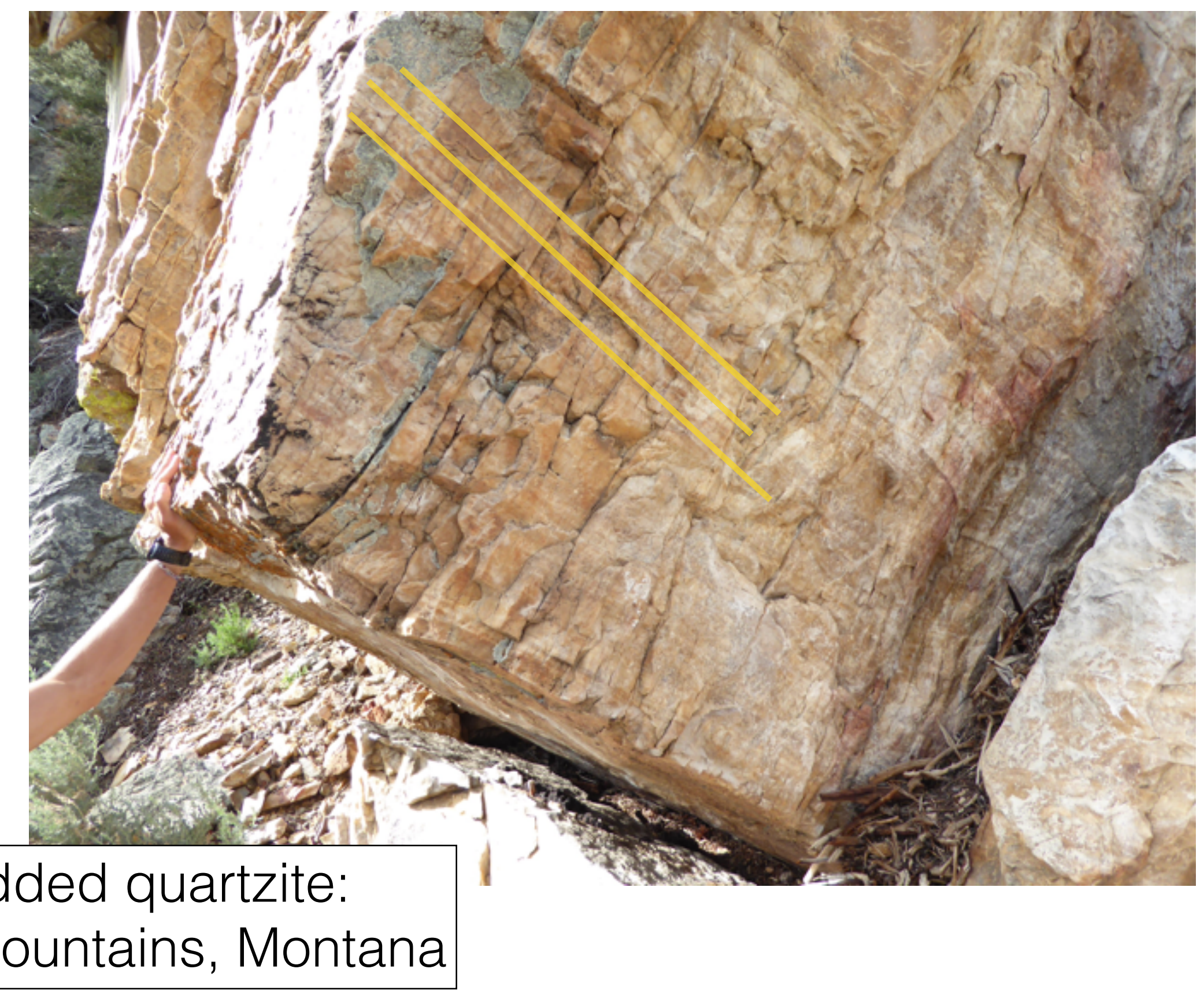




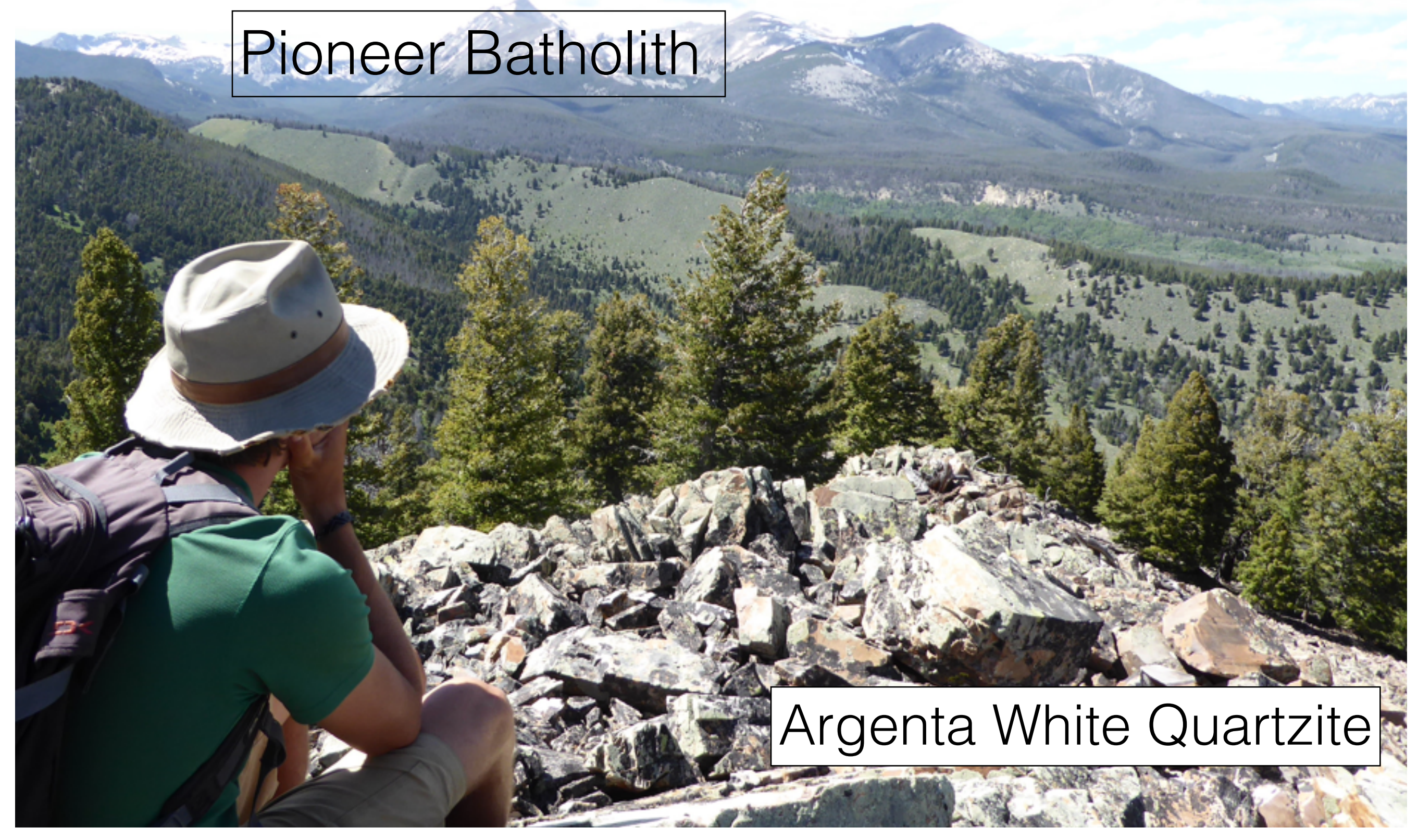




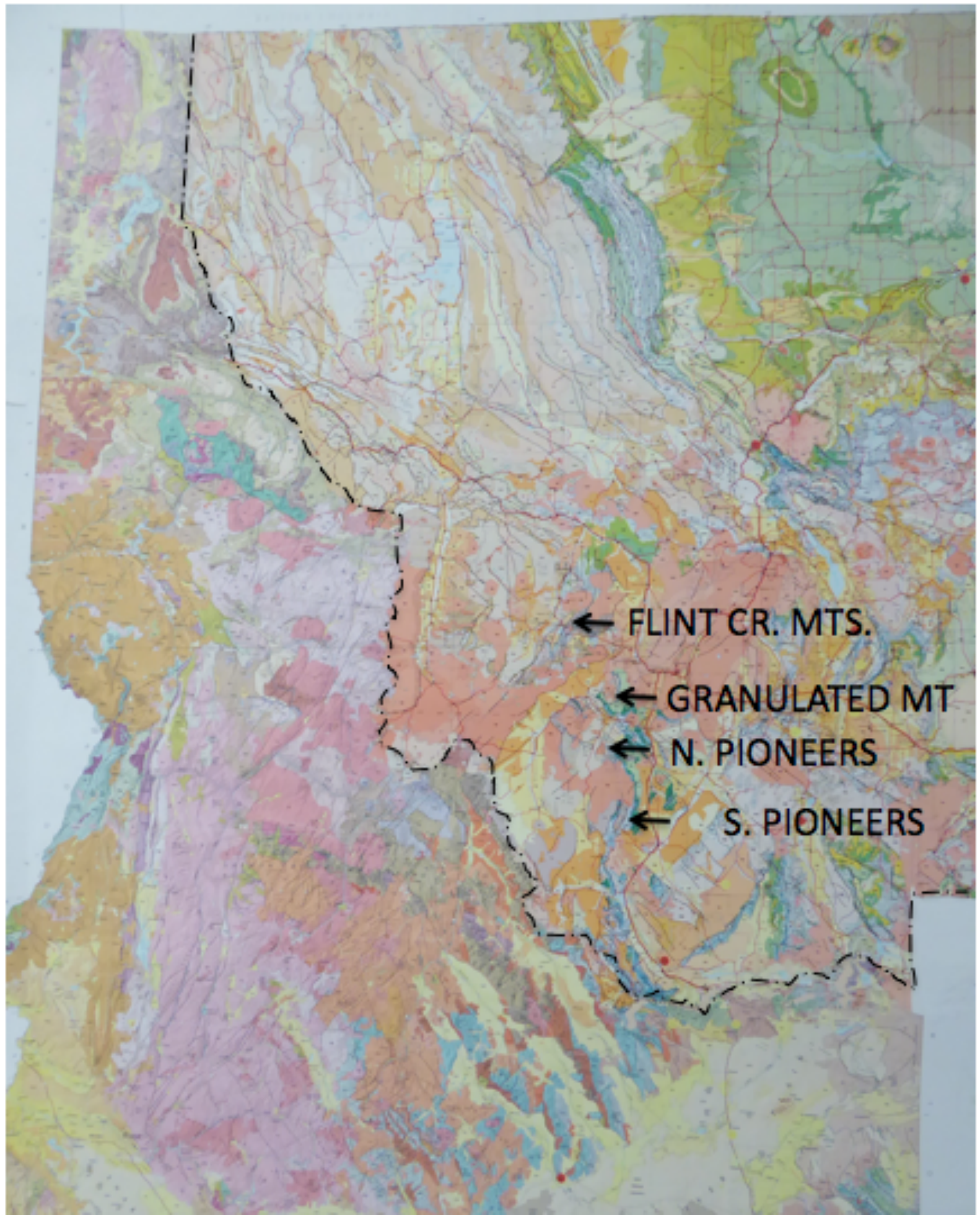

MBMG, IGS 


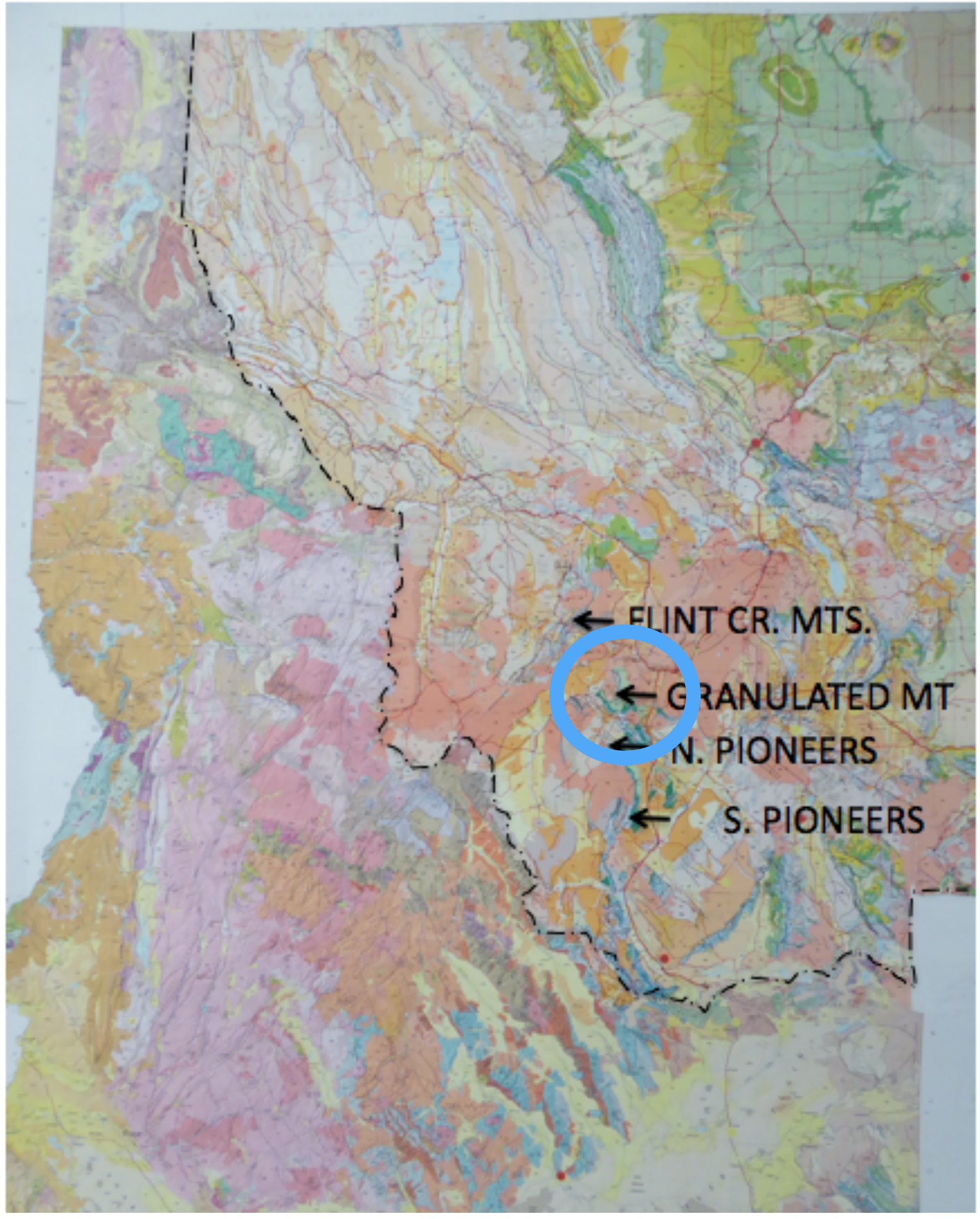

MBMG, IGS 


\section{Granulated Mt. : Butte South Quadrangle}

MBMG, 2012

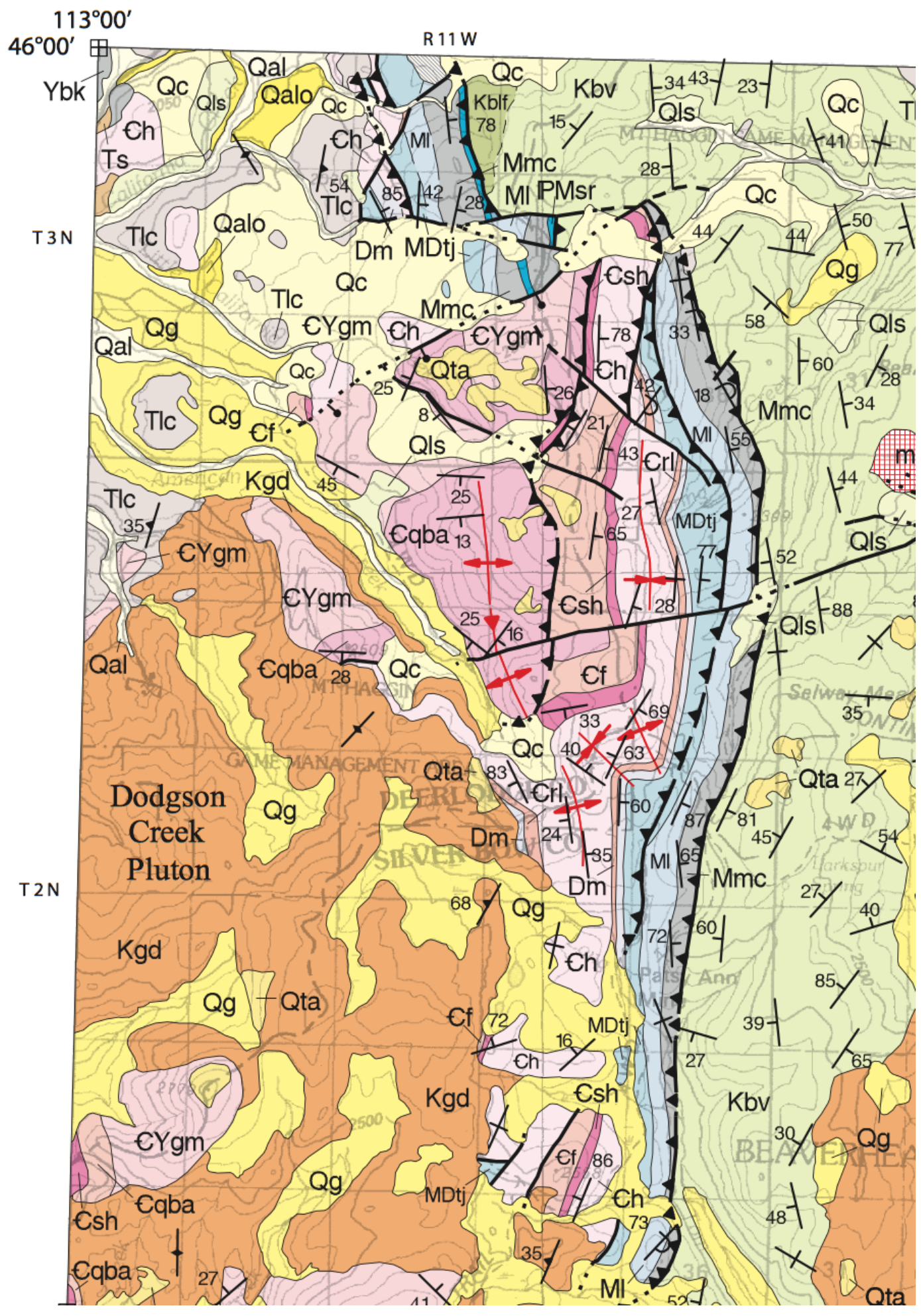




\section{Granulated Mt. : Butte South Quadrangle}

CYgm: Quartzite of Granulated Mt

Cqba: Cambrian argillite and quartzite

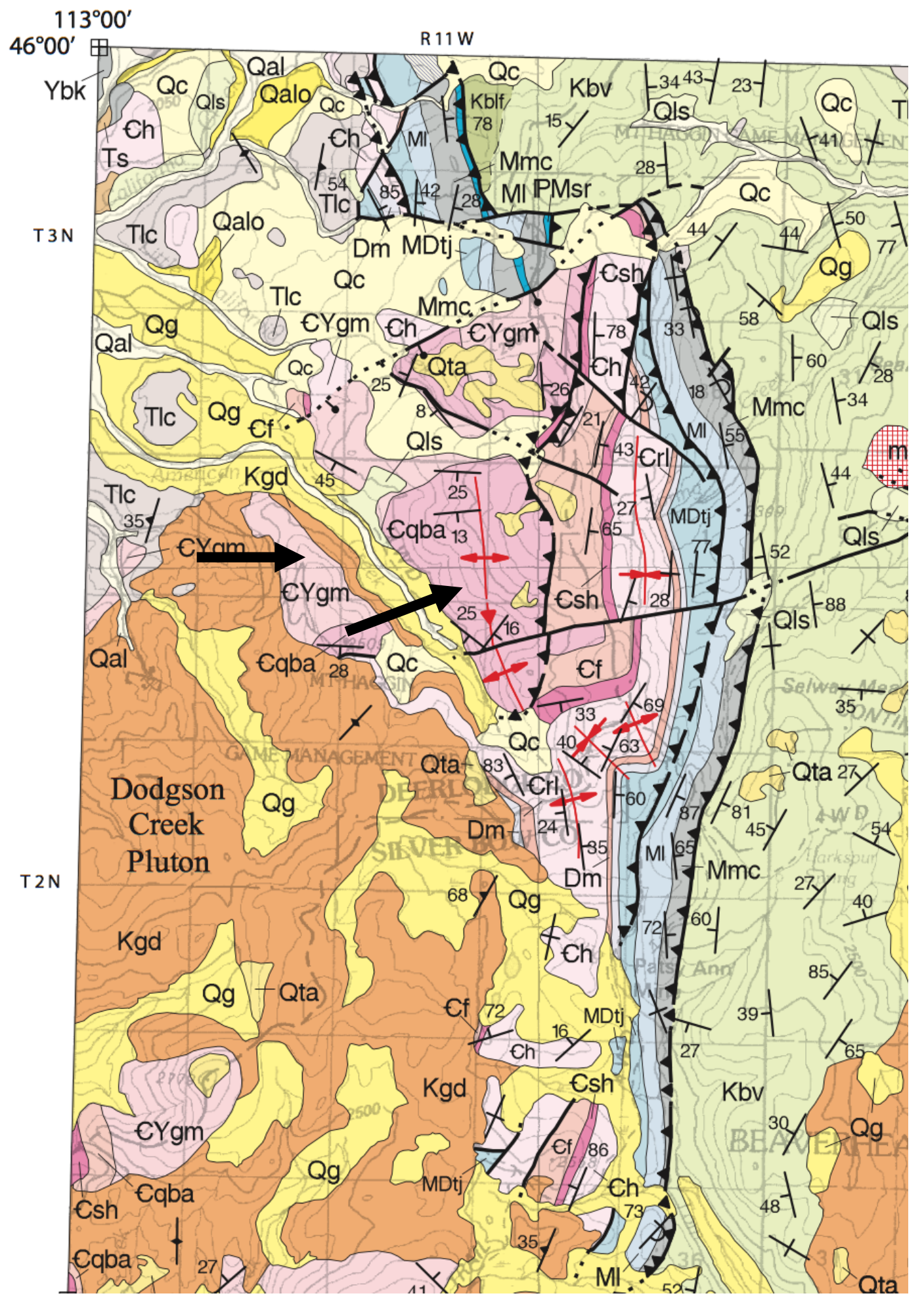




\section{Granulated Mt. : Butte South Quadrangle}

CYgm: Quartzite of Granulated Mt

Cqba: Cambrian argillite and quartzite

Cf: Cambrian Flathead Ss

MBMG, 2012

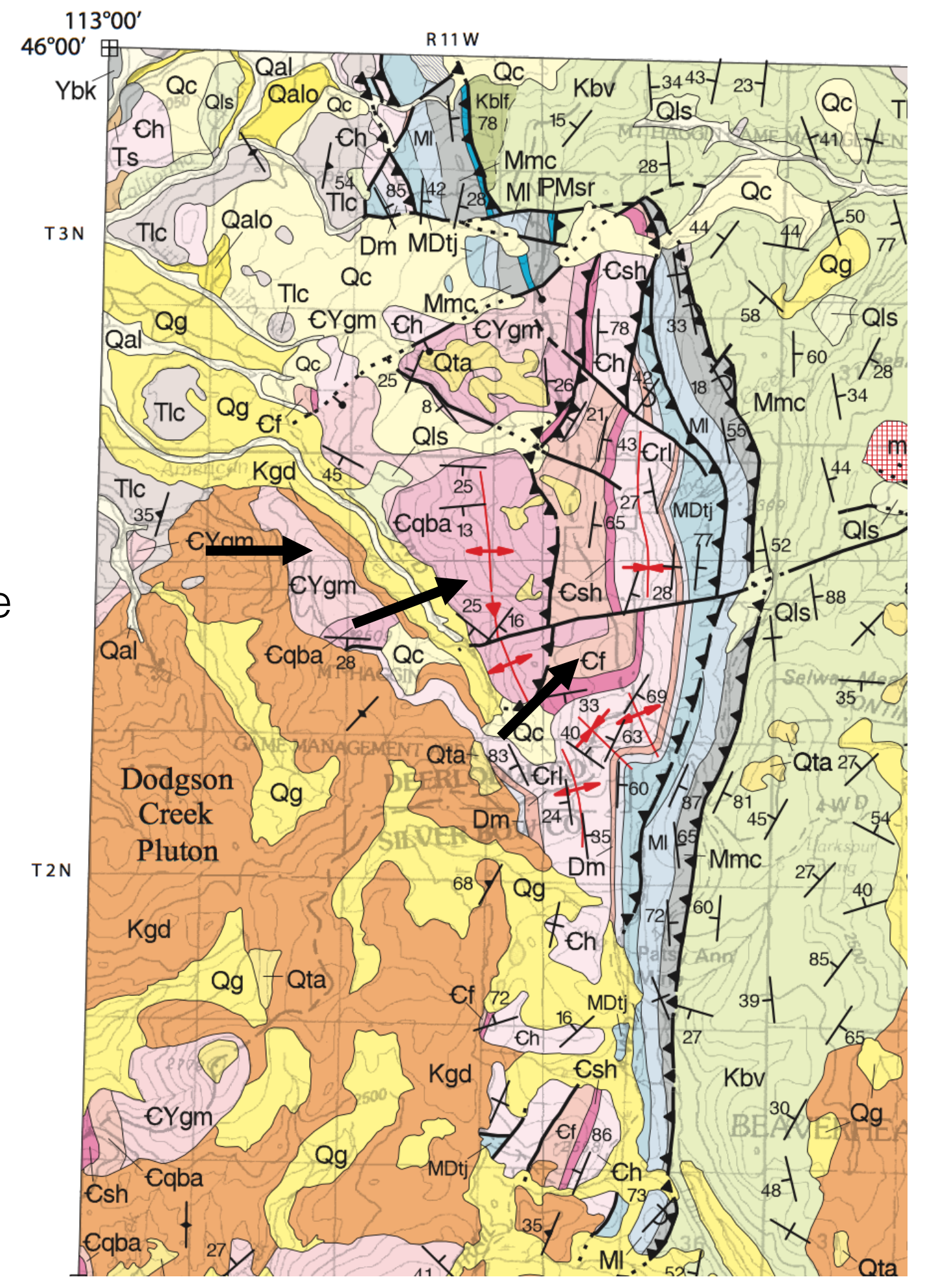




\section{Butte South Quadrangle}

a

Cglq: Quartzite of Grace Lake

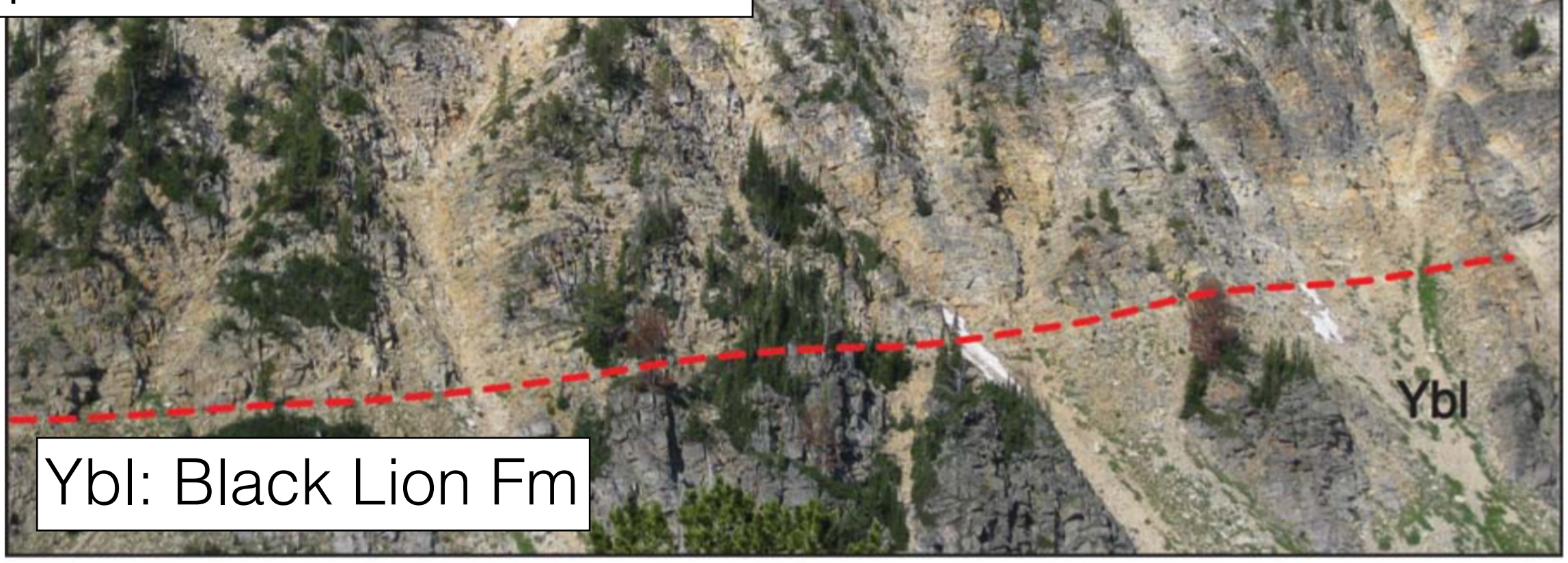




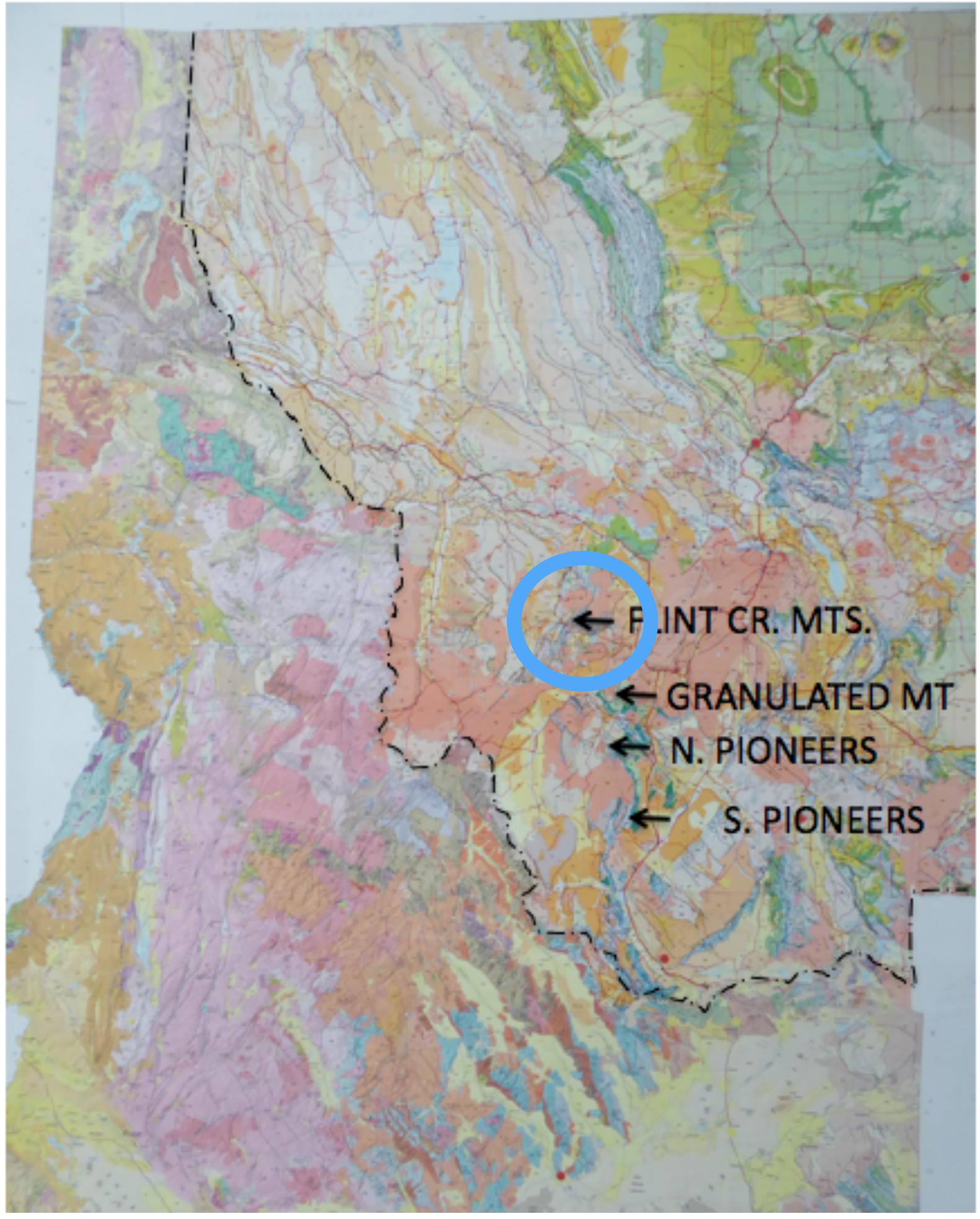

MBMG, IGS 


\section{Flint Creek Mts. : Porter's Corner}

MBMG, 2003

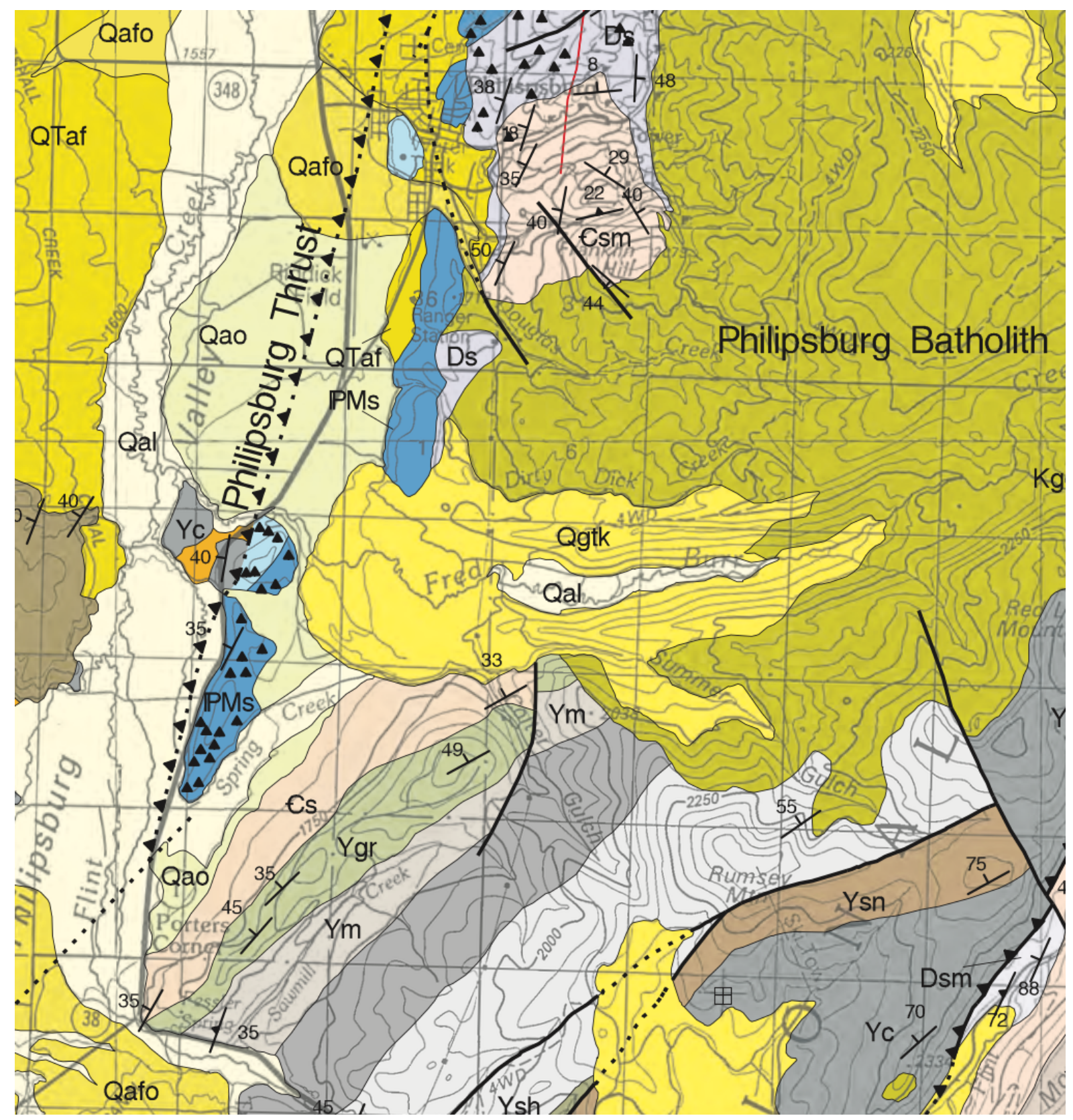




\section{Flint Creek Mts. : Porter's Corner}

Ygr: Garnet Range \& Pilcher Ym: McNamara Formation

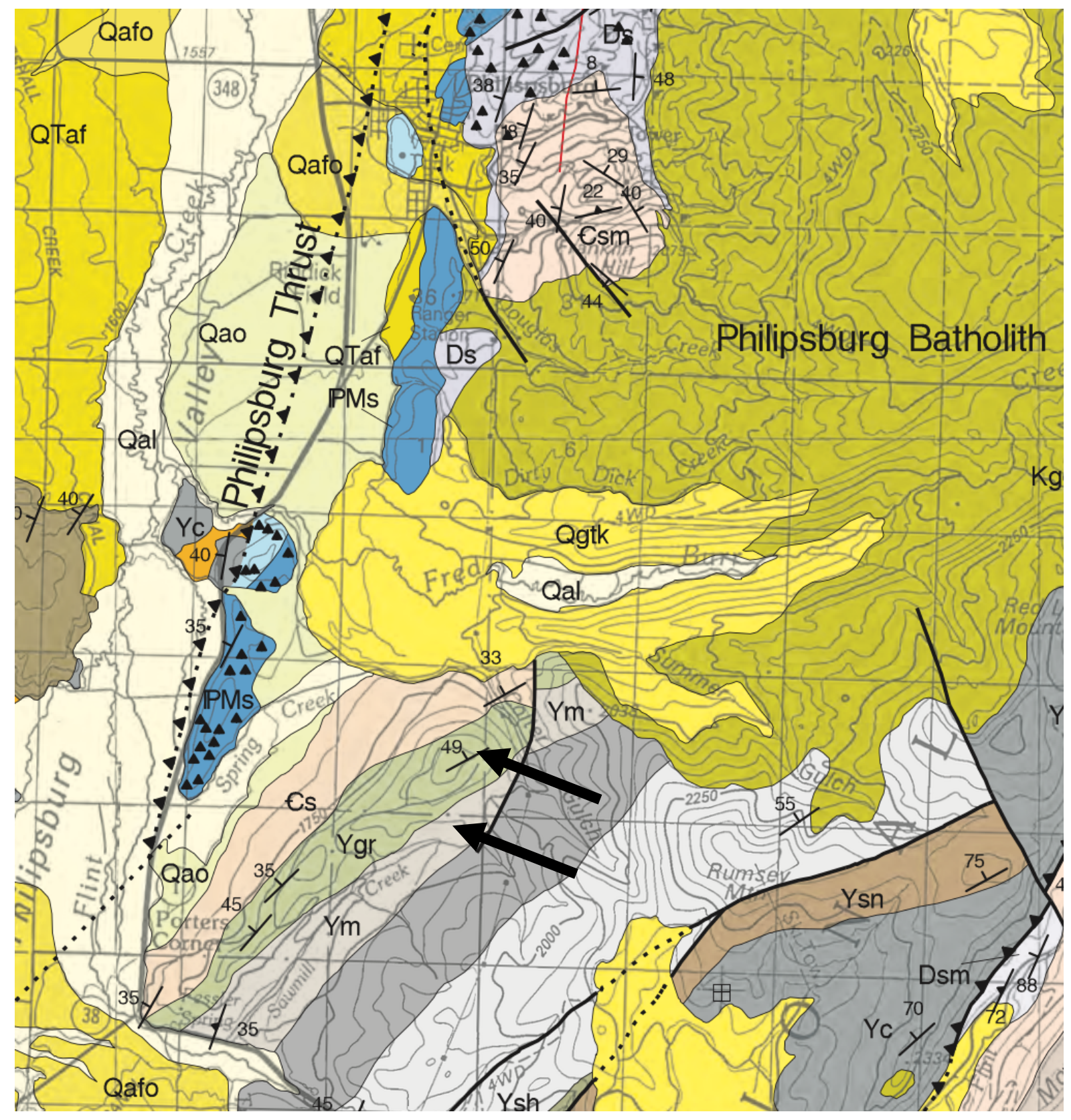




\section{Flint Creek Mts. : Porter's Corner}

Cs: Cambrian sedimentary (includes Flathead Ss)

Ygr: Garnet Range \& Pilcher Ym: McNamara Formation

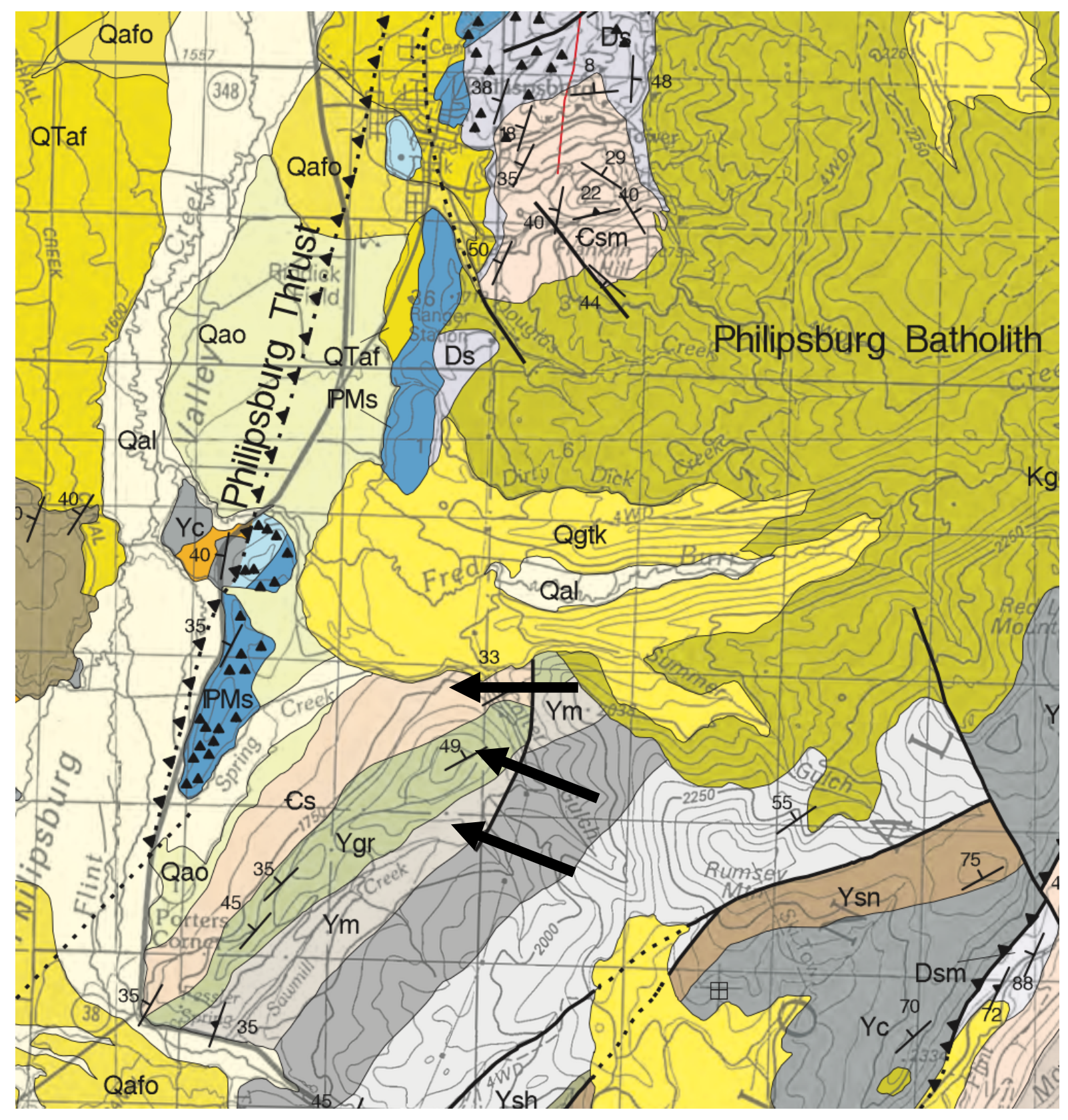




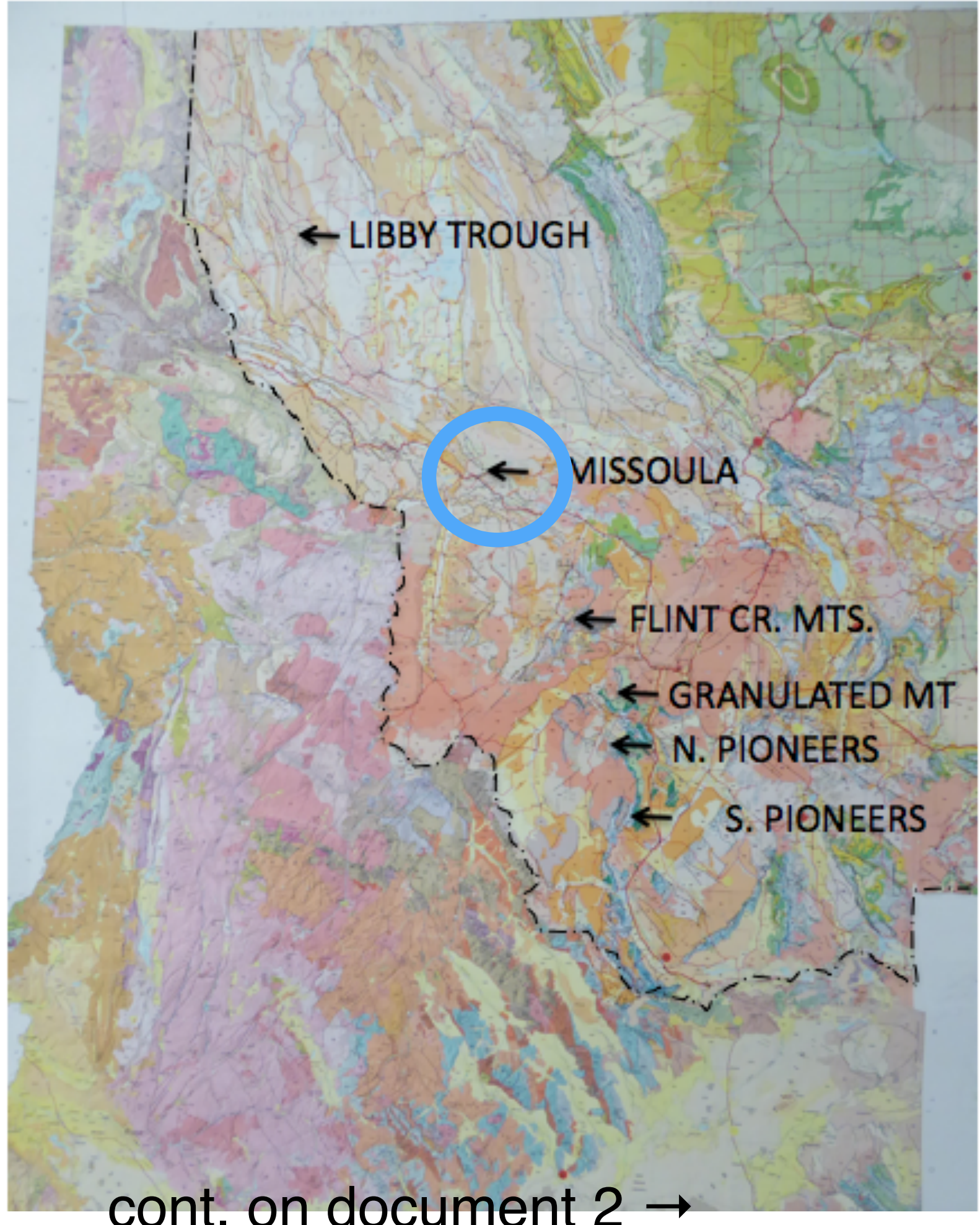

MBMG, IGS 